\title{
TOBY DAMMIT SOB O OLHAR DE FELLINI
}

Maria da Luz Alves Pereira*

Resumo: Este artigo analisa "Toby Dammit", segmento do filme Histoires extraordinaires, dirigido por Federico Fellini, uma adaptação do conto "Never bet the devil your head - a moral tale", de Edgar Allan Poe. O trabalho é norteado por dois objetivos: o primeiro, mais geral, é discutir a adaptação, ressaltando o seu caráter de processo e produto, segundo a acepção de Linda Hutcheon; o segundo, mais específico, é identificar e descrever os niveis de aproximação e de afastamento entre a adaptação e o texto adaptado.

Palavras-chave: Adaptação. Cinema. Recursos estéticos.

E dgar Allan Poe (1809-1849), poeta, contista e ensaísta americano, é um dos autores mais adaptados para o cinema em todos os tempos, conforme The Internet Movie Database (IMDb), uma base de dados sobre filmes, comerciais e séries para televisão, jogos de computador etc. Don G. Smith (2003), renomado estudioso da sua filmografia, declara que, além do universo da literatura e da crítica literária, seus trabalhos também influenciam os mundos da música (Debussy, Ravel, Prokofiev), da arte (Beardsley) e do cinema, em que seus contos de terror e poemas misteriosos frequentemente servem como inspiração. Com 336 produções, Poe é o autor americano que teve por mais vezes a sua obra transformada em obra fílmica. No cenário mundial, ele fica atrás apenas de William Shakespeare, podendo ser ovacionado como o segundo escritor mais adaptado em toda a história do cinema.

Diante do exposto, este artigo se propõe a analisar “Toby Dammit”, dirigido por Federico Fellini, terceiro segmento do filme franco-italiano Histoires extraor- 
dinaires $^{1}$, produzido por Cocinor, Les Films Marceau e Produzioni Europee Associati (PEA) e lançado em 17 de maio de 1968, na França, no Cannes Film Festival. Estamos utilizando a edição brasileira Histórias extraordinárias (2003). Esse segmento é uma adaptação do conto "Never bet the devil your head - a moral tale", de Poe, publicado pela primeira vez no Graham's Lady's and Gentleman's Magazine, em 1841. Este trabalho se justifica por investigar a filmografia de Poe, vertente pouco explorada no meio acadêmico brasileiro, e por procurar contribuir para a alteração da visão negativa da adaptação não raro vista como secundária e inferior por algumas críticas que insistem em uma interpretação depreciativa.

Para compreendermos a adaptação, recorremos aos estudos de Linda Hutcheon, em Uma teoria da adaptação (2011), nos quais propõe uma dupla definição do termo. Primeiro, vista como "uma entidade ou produto formal, a adaptação é uma transposição anunciada e extensiva de uma ou mais obras em particular" (HUTCHEON, 2011, p. 29). Segundo, vista como "um processo de criação, a adaptação sempre envolve tanto uma (re-)interpretação quanto uma (re-)criação, dependendo da perspectiva, isso pode ser chamado de apropriação ou recuperação" (HUTCHEON, 2011, p. 29). Ancorados nesses pressupostos, qualificamos o filme em estudo como "adaptação" por anunciar a sua fonte com a seguinte inscrição: "Da obra de Edgar Allan Poe". Como bem notado, seguindo a sua terminologia, utilizamos o termo "adaptação" para o produto final transposto (filme) e "texto adaptado" para o texto que lhe deu origem (conto).

Hutcheon (2011) faz questão de enfatizar que o processo de adaptação não é uma reprodução, mas, sim, uma interpretação e recriação em uma nova mídia. Nesse processamento, as decisões do adaptador são feitas num contexto criativo e interpretativo que é ideológico, social, histórico, cultural, pessoal e estético. $\mathrm{Na}$ esteira do seu pensamento, consideramos a adaptação um "ato interpretativo e criativo" e, nessa perspectiva, o adaptador é considerado um "intérprete-criador" (HUTCHEON, 2011, p. 156). Para essa estudiosa, a adaptação é um ato de "contar uma história como releitura e reinterpretação" (HUTCHEON, 2011, p. 156) e, para ser experienciada como adaptação, é preciso ser reconhecida, quer dizer, é necessário que o leitor ou espectador conheça seu texto adaptado para poder fazer associações. Para ser uma adaptação bem-sucedida, ela deve satisfazer tanto o público conhecedor quanto o desconhecedor, sendo mais fácil criar uma relação com este último, pois o primeiro tem exigências e, naturalmente, pode inclinar-se a tecer um juízo desfavorável, tendendo a considerá-la aquém de suas expectativas.

A teórica canadense alerta, ainda, para a dupla natureza da adaptação, explicando que, embora elas sejam consideradas autônomas, objetos estéticos em seu próprio direito, elas não deixam de ser recriações, e é assim que deveriam ser teorizadas e estudadas. Essa natureza dupla não implica que deveríamos analisá-las segundo o critério de "proximidade e fidelidade ao texto adaptado" (HUTCHEON, 2011 , p. 28). Por isso, fugindo de uma crítica da fidelidade, buscando uma variedade de perspectivas, especialmente porque estamos lidando com uma obra canônica, procuramos examinar os graus de proximidade que podem ser mais fortes ou mais tênues entre o texto adaptado e a adaptação, detendo-nos nos aspectos pró-

\footnotetext{
O filme Histoires extraordinaires (1968) é composto por três médias-metragens: "Metzengerstein", "William Wilson" e "Toby Dammit", dirigidos por Roger Vadim (1928-2000), Louis Malle (1932-95) e Federico Fellini (1920-93), respectivamente. Para designar cada uma dessas partes, Smith (2003) utiliza o termo "segmento". Seguindo seus passos, adotamos a mesma terminologia e, de maneira similar, usamos itálico quando se refere ao filme e aspas com relação aos segmentos.
} 
prios de cada um, que fazem a adaptação possuidora de uma existência única, e a influência que essa aproximação exerce sobre a adaptação como nova obra.

Entendemos que ao assistirmos à versão cinematográfica, como público conhecedor, temos uma "duplicação interpretativa, um movimento conceitual para frente e para trás entre a obra que conhecemos e aquela que estamos experienciando" (HUTCHEON, 2011, p. 156). Compreendemos, ainda, que o contexto no qual experienciamos essa versão é outro e, portanto, vai interferir no significado e na importância atribuída a ela e, principalmente, que proximidade e fidelidade ao texto adaptado não são critérios de julgamento ou o foco da análise.

O estudo da produção de Fellini, com duração de 44 minutos, requer um conhecimento prévio do texto do qual é originário. Por isso, inicialmente, voltemos olhares para a narrativa literária, seguida da filmica, procurando apreender ambas as fábulas. O conto relata a história do Sr. Toby Dammit, um homem bem-humorado que tem muitos vícios. O pior deles é ser afeito às apostas, prática que o leva à ruína. Por qualquer motivo, ele insiste em apostar a sua cabeça com o diabo. Tudo acontece em um belo dia, quando ele e o seu amigo, o narrador da história, vão passear em direção a uma ponte escura. Quase ao terminar a travessia, encontram um torniquete alto. O amigo passa em volta e Dammit aposta que pode pular, saltando por cima dele, dizendo as palavras de costume. De repente, aparece o diabo que o incentiva a realizar tal experiência. Ao pular, cai de costas ao mesmo tempo que o diabo enrola no seu avental algo que cai nele: a cabeça de Dammit. Por fim, o corpo é vendido pelo amigo como comida para cachorro.

No segmento, o inglês Toby Dammit, um ex-ator shakespeariano cuja carreira está em decadência por causa do alcoolismo, concorda em fazer um western católico em Roma. Um entusiasta de carros de corrida, ele aceita fazer o filme porque está interessado em garantir a Ferrari (último modelo) prometida pela produção. No aeroporto, à sua chegada, ele faz um esforço enlouquecido para escapar das luzes, da multidão e das perguntas dos repórteres. No alto de uma escada rolante, tenta pegar uma bola que vem até ele, mas que volta para uma menina de cabelos dourados que lhe agradece com um sorriso tão estranho, levando-o a experimentar uma premonição e cair em completa angústia. Acompanhado de seus produtores, vai de carro a uma emissora de TV e, nesse percurso, continua a ter visões da menina com a bola. No decorrer de uma cerimônia de premiação, completamente bêbado, foge em sua Ferrari. Na estrada, após desabalada corrida, na frente de uma ponte caída, alguns trabalhadores tentam, com acenos, parar o seu carro em alta velocidade. Dammit faz uma pausa e, em seguida, acelera freneticamente, forçando ultrapassar para o outro lado de um precipício. Dessa temerária ousadia, nada mais se pode ver a não ser um fio de sangue escorrendo, enquanto a menina recolhe em seus braços algo em forma de bola: a cabeça de Dammit.

A película surpreende o espectador que conhece o conto de Poe que the deu origem. Ela faz uma leitura que, à primeira vista, tem poucos pontos em comum com o texto, encontrando respaldo no ponto de vista de Syd Field (2001), que considera que a melhor maneira de fazer uma adaptação é não ser fiel ao original. Uma das explicações para essa dessemelhança pode estar nas considerações de Hutcheon (2011, p. 34) de que as unidades separadas de uma história também podem ser transmidiadas, resumidas em versões condensadas e, até mesmo, "podem perfeitamente mudar - radicalmente, em sua grande maioria - 
durante o processo de adaptação, e não apenas no ordenamento do enredo, embora esse seja o caso mais óbvio".

Além do fato de ter o mesmo nome, o que tem a ver o bem-humorado Dammit de Poe com o beberrão e arrogante personagem de Fellini? Precisamos chegar até o desenlace para descobrir que o texto filmico leva mais que esse elemento do texto adaptado. De modo brando, ele retoma o percurso de um sujeito que enfrenta um estranho misterioso em uma ponte e perde a sua cabeça por causa de uma aposta. Na intenção de compreendermos essas personagens, iniciemos por apreender a gênese do nome que as identificam.

Toby é a forma reduzida de Tobias, versão grega do nome bíblico hebreu Toviyah, que significa “a bondade de Deus". É um nome popular na Alemanha, na Escandinávia, nos Estados Unidos e entre os judeus. Dammit é um trocadilho com a expressão damn it, que quer dizer "dane-se" ou "vá para o inferno". Outra construção possivel é "to be damned" (ou "not to be damned"), significando ser ou não ser um maldito ou condenado, ou, ainda, fadado a ser condenado. Estaria Poe dialogando com a famosa frase shakesperiana "To be or not to be, that is the question"? De qualquer modo, o nome constitui um jogo de palavras e gera sentido a partir da oposição semântica entre elas, ou seja, a significância nasce da percepção da diferença. No nome, está a essência da personagem e a indicação do fim que ela teria como alude o narrador: pronunciar esse nome soava como uma praga. Usando desse recurso de criação de identidade, o autor instaura um discurso irônico à medida que, tendo a personagem um nome de batismo abençoado (Toby), é desgraçada pelo nome de família (Dammit) e vitimizada por causa dessa carga negativa a que está vinculada pelo antropônimo. Resta acrescentar um aspecto: sendo "toby" uma gíria corriqueira nos tempos de Poe, significando "ignorante", "burro", temos que essa personagem pode ser lida como um "tolo" que vai se dar mal. Esse sentido se adequa muito bem ao âmbito escolhido por Fellini, pois a personagem criada por ele almeja conquistar a qualquer preço o prêmio a ela oferecido e, por causa de sua ambição, perde a própria vida.

No segmento, o protagonista Toby Dammit é assumidamente neurótico, não espiritual e consumidor de drogas. Ele se mostra cansado da fama e do apreço ao material e ao superficial que vem junto com a profissão, e está cada vez mais perto de arruinar a sua carreira por abusar do álcool. Ele não se importa com a sua ocupação, mas tão somente com a vida de celebridade, ficando, portanto, o enfoque deslocado, pois as atividades de produção não geram nenhuma importância para ele.

Como a narrativa filmica se propõe a ser uma obra metalinguística, espera-se que as ações girem em torno desse enredo, mostrando o cotidiano de um set de filmagem tão característico nesse tipo de produção que usa a linguagem do cinema para comentar um filme cujas personagens estão fazendo. Todavia, os trabalhos não são mostrados, porque a história não se concentra nos eventos em que Dammit está envolvido, mas em seu próprio caráter e em sua visão de mundo. Por isso, seu olhar é primordial, porque é por meio dele que o espectador toma conhecimento da realidade diegética. Nesse contexto, na contramão da narrativa cinematográfica tradicional, o segmento propõe um novo tipo de tecido narrativo no qual a ação principal aparece constantemente dissolvida nas profundezas dos eventos plausivelmente insignificantes que se desenrolam ao redor, "acontecimentos esses que chegam mesmo a constituir o núcleo de uma nova ação, orien- 
tada no sentido de redescobrir, no tecido dos acontecimentos cotidianos mais irrelevantes, significados ou ausências de significados" (ECO, 1979, p. 327).

Essa personagem, ao apresentar um comportamento totalmente díspar do esperado para um superstar, que, via de regra, procura agradar ao público para se manter na mídia, elucida o pensamento de que "as velhas identidades, que por tanto tempo estabilizaram o mundo social, estão em declínio, fazendo surgir novas identidades e fragmentando o indivíduo moderno, até aqui visto como um sujeito unificado" (HALL, 2003, p. 7). Criticando abertamente a televisão e o cinema, Fellini, indiretamente, explora o tema da identidade cultural na modernidade, possibilitando uma reflexão sobre a "crise de identidade", questão tão discutida na sociologia.

A adaptação atualiza o texto adaptado, deslocando-o para outro contexto. Nesse sentido, consegue captar a modernidade fundamental da história de Poe. Esse deslocamento insere-a no Gótico contemporâneo por sua história ser ambientada em um cenário moderno e, particularmente, por circular em torno de um nexo especial: o problema de assimilação das ansiedades sociais. De certa maneira, não deixa de ter uma estreita conexão com o Gótico urbano, por retratar dramaticamente o caos da cidade, que se apresenta como um lugar de ruínas, paradoxalmente bem desenvolvida e decadente, num estado degradante, que não possibilita plena vida aos seus habitantes, mas tão somente alienação que os leva, inevitavelmente, à paranoia, fragmentação e perda de identidade (WARWICK, 2009, p. 251).

Steven Bruhm (2011) assegura que, de modo algum, o Gótico contemporâneo rompe com o Gótico tradicional que sempre jogou com a cronologia, olhando para trás, ansiando por uma estabilidade social que nunca existiu. Segundo ele, "o que se torna mais acentuado no gótico contemporâneo - e que o distingue de seu antepassado - é o compulsivo retorno de protagonistas e telespectadores a certas fixações, obsessões e bloqueios" (BRUHM, 2011, p. 261, tradução nossa). No caso em estudo, o protagonista age, peremptoriamente, motivado por obsessões. Se, por um lado, a obra de Fellini desloca a história de Poe para um contexto contemporâneo, por outro, resgata o que lhe é de mais precioso: o seu "secreto argumento" (BORGES, 2008, p. 89), a sua essência cômica e peculiar natureza grotesca, sob uma perspectiva satírica. Sua sátira mais explícita volta-se para o meio artístico - cinema e televisão - ao passo que a mais velada se dirige à sociedade italiana.

Pela conduta singular de Dammit, entendemos que ele representa o homem moderno, pois já na sequência introdutória são identificadas no seu interior identidades contraditórias que o empurram para diferentes direções, de maneira que suas identificações estão sempre sofrendo deslocamentos. Por ser uma personagem excêntrica e deslocada, vemo-la ambientada em espaços diversificados como o aeroporto, a televisão e o local de premiação, sempre expondo sua indiferença e seu status de celebridade, comprometendo a sua reputação. A sequência do aeroporto sofre vários cortes, infundindo um interminável desfile de cenas com pinceladas grotescas, por apresentarem coisas e elementos desordenados que não participam do mesmo meio. Montada sob a concepção de simultaneidade, o diretor/montador, reunindo certo número de fatos sem liame entre

2 No original: "what becomes most marked in the contemporary gothic - and what distinguish it from its ancestor - is the protagonists' and the viewers' compulsive return to certain fixations, obsessions, and blockages". 
si, "empenhar-se-á em despertar uma impressão cósmica, uma visão de conjunto da existência, uma visão total do mundo..." (FAURE apud AGEL, 1982, p. 51).

$\mathrm{Na}$ continuidade, é idealizada uma sequência na qual são mostrados aspectos da vida moderna. Quanto mais situações do cotidiano são veiculadas, através de uma visão microscópica, tanto mais os contornos se confundem. O mundo revelado sob os olhos de Dammit através da vidraça do carro se revela opaco e caótico. Como o inconsciente continuamente interfere na percepção do mundo, esse protagonista do gótico contemporâneo muitas vezes experimenta sensações misturadas, por estarem presas numa simultaneidade de eventos: um traveling para frente persegue por alguns segundos um caminhão com a traseira aberta, deixando à mostra um carregamento de partes de carne bovina expostas ao lado de um homem em pé com a camisa aberta com o peito à vista. Uma vez mais, deparamo-nos com Fellini recuperando o grotesco inscrito no texto de Poe, não exatamente por ser uma mistura dos mundos humano, animal e vegetal, que caracteriza esse tipo de manifestação, mas por aproximá-los de maneira gritante. Com essa aproximação, fazendo uma exposição do homem como mercadoria, o segmento procura apontar, por meio de anamorfose, o equívoco dos sentidos e do mundo das aparências. Em Fellini, como que se materializa uma reação ao pensamento cartesiano ao derruir as categorias de um mundo aparentemente ordenado. Nessa visão grotesca, "o fantástico, monstruoso, macabro, excêntrico, obsceno invadem nossa realidade cotidiana, as suas leis de repente estão suspensas, a ordem habitual das coisas se desfaz" (ROSENFELD, 1973, p. 61). Tendendo a igualar o homem ao animal, ele já não se difere da criatura irracional e tampouco dos objetos, tanto que em seguida se vê, sob a habilidade de uma rápida panorâmica para a esquerda, a exibição de uma loja em que o brilho e a leveza dos lustres pendurados para venda contrastam com a cena anterior.

A descrição dessas imagens faz-nos pensar que essa não é uma tarefa fácil para o analista, apesar de sua aparente simplicidade. Tanto que a nossa tentativa consegue ser mais distendida que as próprias imagens, que, na sua totalidade, não duram mais que poucos segundos e, por causa de sua complexidade, exigem muitas palavras para serem descritas, deixando extenso por demais o texto verbal. Diante desse obstáculo, "ao analista só resta tentar, em um 'desespero ético', competir com o objeto que procura compreender” (STAM, 2003, p. 210). Esse fato ocorre porque

[...] não se trata de descrever "objetivamente" e de maneira exaustiva todos os elementos presentes em uma imagem, de modo que o método utilizado na descrição sempre procederá, no fim das contas, a uma materialização de uma hipótese de leitura, explícita ou não"3 (AUMONT; MARIE, 1990, p. 73, tradução nossa).

Fellini, com suas idealizações, coloca-nos diante dessa incapacidade de apreender e traduzir em linguagem verbal os elementos informativos e significativos da linguagem filmica, levando-nos a crer que, por mais que tentemos, nossa descrição é sempre uma "hipótese de leitura" e nunca um retrato fidedigno da imagem.

Tentando desmascarar a sociedade romana, o segmento pretende reavivar uma premissa há muito em evidência aos modernistas: “A ordem é apenas aparente, no

3 No original: "no se trata de describir 'objetivamente' y de manera exhaustiva todos los elementos presentes em una imagen, de modo que el método utilizado en la descripción siempre procederá, a fin de cuentas, de la materialización de una hipótesis de lectura, sea ésta explícita o no". 
fundo reina o caos. Reais, verdadeiros são as ruínas e os esgares atrozes. Agitamo-nos num mundo de aparências, de máscaras, num mundo que é 'representação"' (ROSENFELD, 1973, p. 66). Ao representar essas realidades, mostra a cosmovisão de seu diretor que talvez queira indicar que o homem tende a viver equilibrado na corda bamba, manipulado pelas normas de conduta sociais, sendo "um mero detalhe, um mero fragmento do material do mundo" (DELLUC apud JAKOBSON, 1970, p. 154). Vivendo de aparências, ele está fadado à falência dos sentidos e valores, e só lhe resta o nada, fim esse implícito no desfecho.

Retomando a questão espacial, observa-se que quase todos os locais onde são ambientadas as ações tomam o aspecto do não lugar, do não identitário. Marc Augé (1997, p. 69) designa por "lugar e não-lugar [...] espaços reais e a relação que seus utilizadores mantêm com esses espaços”. Nessa acepção, o lugar é definido como 1. "identitário": alguns indivíduos podem se reconhecer nele; 2. "relacional": alguns indivíduos podem ver nele a relação que os une; 3. "histórico": seus ocupantes podem encontrar sinais de filiação. Um não lugar é definido como um espaço no qual nem a identidade, nem a relação nem a história sejam simbolizados.

No presente caso, o que se observa da relação de Dammit com todos os ambientes nos quais circula é sempre uma não identificação, marcando-os como não lugares, onde ele é apenas um estranho. A ausência no espaço produz um distanciamento do lugar, provoca o estranhamento e, por conseguinte, a desestabilização da identidade. Essa apresentação do protagonista leva-nos a compreender que a vida de celebridade não é tão glamourosa quanto parece ser e que poucos artistas ousam agir variadamente do comportamento tido como politicamente correto. Tendo em mente que a identidade está estreitamente ligada ao lugar e, nesse caso, estando a personagem abalada, o segmento abre o questionamento acerca das práticas sociais existentes cuja interação se dá face a face e aponta para a diluição das fronteiras como um elemento de distanciamento da ligação da identidade com o lugar.

O que não consegue passar despercebido do espectador, mesmo daquele mais ingênuo, é o tom chocante predominante na sequência introdutória. À medida que são mostradas cenas entrecortadas, pode-se sentir a relevância das cores na caracterização da espacialidade. Para conseguir os efeitos de angústia e tédio, o diretor abusa das cores quentes como o amarelo, laranja e vermelho em contraste com as cores opacas das roupas das pessoas e do negro do teto do aeroporto. Ao compor o espaço com essas cores, ele o está dotando igualmente de vários efeitos de sentidos, de várias conotações. A saturação das cores nessa sequência intensifica a proximidade do espectador com o espaço, levando-o a ter a sensação de estar em um inferno, um lugar de desassossego, confusão e gritaria, um lugar onde habitam os demônios. Não é por coincidência ser esse o local eleito para a primeira aparição da menina. Ao povoar essas cenas de tons vermelhos, num movimento proléptico, a adaptação já indicia que na caminhada que faz o protagonista ele encontrará a morte. No decorrer da película, é dada preferência ao preto e branco, justificados por razões de adequação dramatúrgica. Com função simbólica, a escolha dessas cores, nesse caso, corrobora tanto a obscuridade das sequências quanto o destaque das ações da personagem principal, sendo o preto e branco metáfora do cinzento da vida de Dammit.

A respeito do local do show de premiação, em poucas palavras, pode-se dizer que a unicidade de tempo (poucas horas), de lugar (salão, palco e piscina artifi- 
cial) e psicológica (celebração e decadência) realçam a capacidade criativa de Fellini quanto à ambientação. Esse local pequeno e fechado, bem aos moldes dos recintos claustrofóbicos de Poe, destinado a concentrar a atenção do espectador mais nas ações e no estado psicológico de Dammit que nos eventos em si, tidos como de menor importância, é um espaço dramático privilegiado, uma espécie de local em que se extravasam as emoções.

Seguindo a tendência expressionista que se baseia "numa visão subjetiva do mundo, na tradução da interioriade, expressas pela deformação, pela estilização, pela abstração e pelo simbolismo" (BETTON, 1987, p. 54), é conferida a esse ambiente uma atmosfera febril por meio de um desmedido aumento ou diminuição das coisas. Por exemplo, as roupas e os acessórios utilizados pelas modelos no desfile são exagerados. Em contrapartida, os móveis, objetos e demais elementos que compõem o cenário, como uma piscina visivelmente artificial e talvez desnecessária, são simplificados, deformando o que seria um ambiente destinado a um show de premiação de artistas famosos. Nessa perspectiva, encontramos o cenário sendo construído para desempenhar o papel de contraponto simbólico ao drama da personagem principal. Aqui, estamos utilizando o vocábulo "contraponto" não no sentido etimológico, mas na acepção de Martin (1990, p. 65), como "o confronto entre dois processos expressivos com o mesmo conteúdo significativo, mas em dois registros plásticos diferentes".

Dammit é um homem vazio, consumido pela frivolidade e adulação, em processo de pactuar com o diabo. Essa entrega nunca é afirmada, porém sugerida por meio de subtexto, simbolismos e metáforas. O diabo é vislumbrado através de uma menina cativante de cabelos longos e louros, vestida de branco, que aparece periodicamente brincando com uma bola, notada apenas por Dammit (Figura 1). A sua imagem pálida com lábios rosados, adicionando-se aos traços grotescos de Dammit, marca a natureza gótica da película, e é capaz de causar os mais instigantes arrepios até mesmo no espectador mais insensível. Essa personagem intrigante surge, repentinamente, em momentos bem significativos.

Figura 1 - Menina-diabo (2003, 1:25'17”)

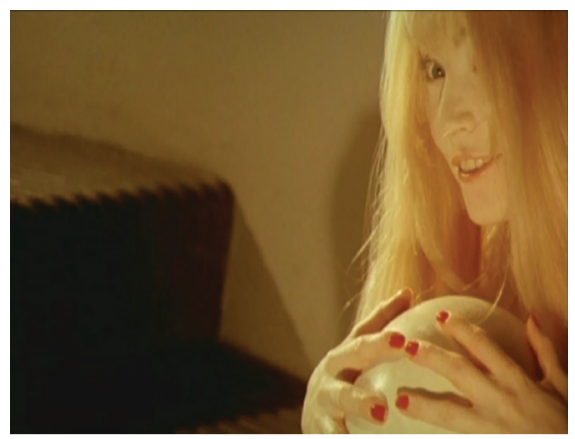

Na sua primeira aparição, com um olhar atento, conseguimos visualizar quase imperceptiveis as suas unhas pintadas de vermelho, o que nos faz pensar em um diabo de dupla face que carrega a inocência de uma criança e a malícia de uma mulher. Nessa sequência, é notável como Fellini leva a efeito o cinema como "a arte da elipse" (MARTIN, 1990, p. 75) ao procurar sugerir mais que mostrar: não 
vemos a menina jogando a bola, tampouco a pegando de volta; não temos assertivas do tipo "aposto minha cabeça com o diabo", tão reiteradas no conto; avistamos apenas a mão dele estendida em sua direção e ela abraçando a bola, sorrindo sutilmente. Pode-se inferir que a mão espalmada, o abraço e o sorriso são metáforas do pacto entre eles, que não é verbalizado, apenas sugerido. O que se vê na tela é significativo o suficiente para que o diretor, confiando na capacidade do espectador de fazer associações, o leve a apreender a alusão ao diabo. Deixando transparecer um habilidoso trabalho de decupagem, essa sequência ilustra bem o pensamento de que "tal capacidade de evocação em meias-palavras é um dos segredos do espantoso poder de sugestão do cinema" (MARTIN, 1990, p. 76).

Durante a entrevista no talk show, ao ser interpelado se tem crença em Deus, Dammit responde que não e, ao ser indagado se acredita no diabo, diz que sim, acrescentando que já o viu. Suas palavras deflagram a segunda visão em flashback: um leve plongée é responsável por mostrar a rápida imagem da menina com os cabelos entreabertos caídos sobre o rosto, o suficiente para deixar ver o seu manso sorriso enquanto, a pedido da entrevistadora, a sua voz-over descreve o diabo como um ser simpático e alegre.

Essa declaração, associada à imagem, é a confirmação do que ficou no campo elíptico na sequência anterior. O diabo de Fellini, aos moldes de Poe, é timidamente galanteador, atraindo Dammit para a autodestruição. A sua fuga nos momentos derradeiros é metade uma tentativa de escapar da própria vida e metade uma busca do diabo que tanto o persegue. É, ainda, a única maneira encontrada por ele de afirmação pessoal, que "consiste na desobediência às proibições, em fazer valer o interdito, mesmo que, para isso, o indivíduo [ele] tenha de arcar com o ônus da morte, do confinamento ou da exclusão" (LOPONDO, 2003, p. 217). Ainda que expressa no contexto de Santareno, essa enunciação é totalmente aplicável a Dammit, mesmo porque ele, excluindo-se e confinando-se em seu próprio mundo, não pode escapar da tentação de seu sedutor e, inocentemente, abraça o que lhe é facilmente oferecido como prêmio: a morte.

Ao longo de todo o segmento, nota-se como a iluminação é utilizada para ressaltar rostos, principalmente o de Dammit. Sobretudo na sequência final, esse recurso mostra-se mais eficaz com o primoroso trabalho de Giuseppe Rotunno ao obter uma fotografia bem contrastada, que modula os claros e os escuros com precisão. A utilização unilateral da luz, em particular, contribui fortemente para criar a impressão de peso sufocante que domina o segmento. Dammit tem o rosto desumanizado e retalhado pela mancha obscura que se forma pelas luzes (Figura 2). A iluminação e o escurecimento de seu rosto, dando a impressão visual de divisão da pessoa, igualmente sugerem a desestabilidade emocional e psicológica da personagem, corroborando a dramaticidade da história. Tendo como significação elíptica esconder a outra face de Dammit, a utilização do efeito de sombra pode deixar entrever um poderoso fator de ansiedade pela ameaça do desconhecido que ele vai enfrentar no plano seguinte. Nessa sequência, com a preocupação de compor uma atmosfera que sugira as vibrações da alma da personagem por meio de um jogo de luzes, vê-se claramente a influência da tradição do claro-escuro do cinema germânico no cineasta italiano.

Outra demonstração da habillidade de Fellini no manejo dos recursos estéticos é ainda vizualizada nessa sequência. Após Dammit descer do carro e olhar o quadro desolador e pavoroso da ponte caída, do outro lado, quase como 
uma miragem, o plano geral oferece uma visão da menina-diabo, no centro do vídeo, com a bola no alto da cabeça, dançando com a graça e a desenvoltura de uma bailarina, atuando num ritual de sedução. A esse respeito, recordamos as proposições de Poe em sua "Marginalia" (1844-49/1984) ao defender a "deformidade de desproporção" e a combinação da "beleza" e da "deformidade" como material de arte. Nesse ensaio, ele anuncia que a beleza é fabricada não somente tendo o belo como inspiração, mas sua origem pode, sim, estar na deformidade: é dessa rica e poderosa combinação que nasce a harmonia do trabalho criativo. A imaginação pura de Fellini, ao colocar lado a lado o belo e o disforme nessa cena, leva-nos a perceber que, orientado pelas fundamentações de Poe, ele tem ciência do poder dessa combinação, que bem utilizada pode ocasionar efeito artístico de valor inestimável. Tanto que a imediata reação de regozijo de Dammit ao contemplar inigualável cenário, captado pelo primeiríssimo plano, é impressionante.

Figura 2 - Dammit dividido (2003, 1:55’17”)



Retomando a importância da iluminação, observa-se que, enquanto Dammit é parcialmente apagado pela sombra e obscuridade que dominam as cenas, a menina-diabo em todas as aparições é realçada pela luz que ilumina o seu rosto terrificante. Esse recurso atua para demonstrar que, ao passo que ele está confuso, num total estado de torpor, ela está determinada, com clareza das ações. Esse jogo de luz, pondo em evidência uma personagem em relação à outra, causa efeito de fatalidade e restabelece o espírito gótico do segmento. Num plano simbólico, a metade sombreada da face dele sugere o nível de terror no qual está imerso e a sua completa impotência para resistir às investidas de seu tirano carrasco.

Após esse último encontro, o sorriso de entrega no rosto de Dammit vai se esvaindo e toma lugar um riso histérico que se junta novamente ao ronco do motor que ele acabara de ligar. À medida que acelera freneticamente o carro e mergulha no abismo aberto pela queda da ponte, a tela se enche em completa obscuridade e o silêncio total toma lugar. Entendemos que esse "silêncio" não é somente uma ausência de sons reais, mas tem valor de "um objeto acústico 
DOSSIÊ

exatamente como a fala, a tosse ou os rumores da rua" (JAKOBSON, 1970, p. 157). E como "fala" se reveste de significação: é como se nos perguntássemos: e agora? O que se sucedeu? A resposta vem poucos segundos depois, quando a imagem vai abrindo-se lentamente, permitindo, por meio do primeiro plano, a visão de um fio manchado de sangue (Figura 3), enquanto o plano de conjunto capta o movimento da bola vindo em direção da câmera até parar ao lado da cabeça de Dammit (Figura 4), separada do corpo, ressaltada pela precisão do primeiro plano. A nitidez do mesmo plano se encarrega de revelar o olhar de vitória do Diabo e de realçar os seus movimentos calculados: enquanto tem uma mão apoiada na bola, a outra pega a cabeça de Dammit. Aqui temos a alusão ao conto. A troca da bola pela cabeça, entre outras, retém a seguinte significação: a parte vital do corpo humano passa a ser objeto, agora o novo brinquedo de estimação do Diabo.

Figura 3 - O fio cortante (2003, 1:58'07”)

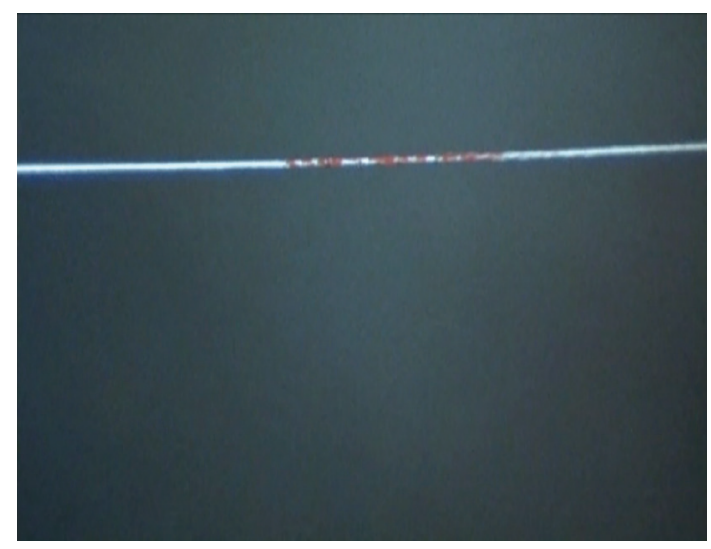

Figura 4 - A cabeça de Dammit (2003, 1:58'19”)

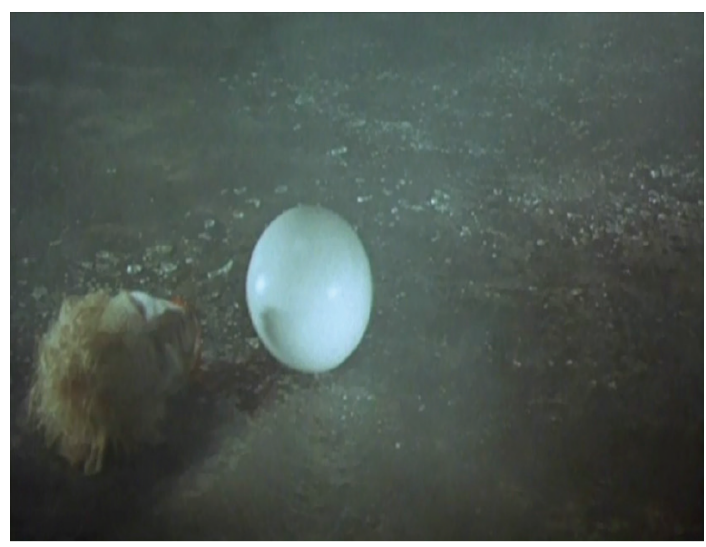

Essa corrida para a morte faz-nos recordar outras personagens de Poe que tiveram destino similar. Diversamente de suas expressividades de pavor carac- 
terísticas, não se lê o medo no rosto de Dammit que é atraído inocentemente e se encaminha com uma lânguida compleição em direção à morte. Moldando-se no horror e retomando o caráter fabular do conto de Poe, esse fim instiga o espectador a se perguntar se esse dificil caminho é o melhor para uma estrela de cinema aprender sobre os males do sucesso e se é um destino apropriado para um homem que tratou a vida em um campo de jogos sem sentido. De qualquer maneira, com ou sem respostas para essas indagações de natureza moral, o espectador pega carona com Dammit na estrada da destruição e é levado a sentir, nesse final simbólico, a opressão de um poço vazio.

\section{Toby Dammit under Fellini's LooK}

Abstract: This article analyzes "Toby Dammit", segment of the film Histoires extraordinaires, directed by Federico Fellini, an adaptation of the short story "Never bet the devil your head - a moral tale", by Edgar Allan Poe. The work is guided by two goals: the first, more general, is to discuss the adaptation, highlighting its character of process and product, according to the acceptation of Linda Hutcheon; the second, more specific, is to identify and describe the levels of approach and distancing between adaptation and the adapted text.

Keywords: Adaptation. Aesthetic resources. Cinema.

\section{REFERÊNCIAS}

AGEL, H. Estética do cinema. Tradução Armando Ribeiro Pinto. São Paulo: Cultrix, 1982.

AUGÉ, M. Por uma antropologia dos mundos contemporâneos. Tradução Clarisse Meireles e Leneide Duarte. Rio de Janeiro: Bertrand Brasil, 1997.

AUMONT, J.; MARIE, M. Análisis del film. Tradução Carlos Losilla. Barcelona: Ediciones Paidós Ibérica, 1990.

BETTON, G. Estética do cinema. Tradução Marian Appenzeller. São Paulo: Martins Fontes, 1987.

BORGES, J. L. Discussão. Tradução Josely Vianna Baptista. São Paulo: Companhia das Letras, 2008.

BRUHM, S. The contemporary gothic: why we need it. In: HOGLE, J. E. The Cambridge companion to gothic fiction. Cambridge: Cambridge University Press, 2011. p. 259-276.

ECO, U. Apocalipticos e integrados. Tradução Geraldo Gerson de Souza. São Paulo: Perspectiva, 1979.

FIELD, S. Manual do roteiro: os fundamentos do texto cinematográfico. Tradução Alvaro Ramos. Rio de Janeiro: Objetiva, 2001.

HALL, S. A identidade cultural na pós-modernidade. Tradução Tomaz Tadeu da Silva. Rio de Janeiro: DP\&A, 2003.

HISTÓRIAS EXTRAORDINÁRIAS. "Metzengerstein": Direção: Roger Vadim. Produção: Ludmilla Goulian; Andre Culted. Roteiro: Roger Vadim; Pascal Cousin. 
Fotografia: Claude Renoir. Figurino: Jean Andre. Música: Jean Prodromides. Montagem: Helene Plemiannikov. Intérpretes: Jane Fonda; Peter Fonda; Carla Marlier. "William Wilson": Direção e roteiro: Louis Malle. Produção: Tomaso Sagone. Fotografia: Tonino Deli Colli. Figurino: Ghislain Uhry. Música: Diego Masson. Montagem: Franco Arcalli; Suanne Baron. Intérpretes: Brigitte Bardot; Alain Delon; Katia Cristina. "Toby Dammit": Direção: Federico Felline. Produção: Tomaso Sagone. Roteiro: Federico Felline; Bernardino Zapponi. Fotografia: Giuseppe Rotunno. Figurino: Pierro Tosi. Música: Nino Rota. Montagem: Ruggiero Mastroianni. Efeito especial: Joseph Nathanson. Intérpretes: Terence Stamp; Salvo Randone; Fabrizio Angeli. França: Films Marceau; Concinor; Pea Cinematografica, 2003. DVD (121 min.), widescreen, colorido, legendado.

HUTCHEON, L. Uma teoria da adaptação. Tradução André Cechinel. Florianópolis: UFSC, 2011.

JAKOBSON, R. Decadência do cinema? In: JAKOBSON, R. Linguística. Poética. Cinema. Tradução Francisco Achcar. São Paulo: Perspectiva, 1970. p. 153-161. LOPONDO, L. A autoconsciência da personagem trágica: uma tentativa de análise. In: LOPONDO, L.; BASTOS, N. M. O. B. (Org.). Língua e literatura. São Paulo: Scortecci, 2003. p. 203-222.

MARTIN, M. A linguagem cinematográfica. Tradução Paulo Neves. São Paulo: Brasiliense, 1990.

POE, E. A. Never bet the devil your head - a moral tale. Graham's Lady's and Gentleman's Magazine, 1841.

POE, E. A. Marginalia. In: POE, E. A. Essays and reviews. New York: The Library of America, 1984. p. 1309-1472.

ROSENFELD, A. Texto/contexto: ensaios. São Paulo: Perspectiva, 1973.

SMITH, D. G. The Poe cinema: a critical filmography of theatrical releases based on the works of Edgar Allan Poe. North Carolina: McFarland \& Company, 2003. STAM, R. Introdução à teoria do cinema. Tradução Fernando Mascarello. Campinas: Papirus, 2003.

THE INTERNET MOVIE DATABASE - IMDb. Disponivel em: < http://www. imdb.com/name/nm0000590/?ref_=nv_sr_5>. Acesso em: 2 jul. 2016.

WARWICK, A. Urban gothic. In: MULVEY-ROBERTS, M. The handbook of the gothic. England: Palgrave Macmillan, 2009. p. 251-252.

Recebido em novembro de 2016.

Aprovado em janeiro de 2017. 